\title{
On Modeling Telecommuting Behavior: Option, Choice, and Frequency
}

\author{
Palvinder Singh \\ The University of Texas at Austin \\ Dept of Civil, Architectural and Environmental Engineering \\ 1 University Station C1761, Austin TX 78712-0278 \\ Phone: 512-471-4535, Fax: 512-475-8744 \\ E-mail: palvinder@mail.utexas.edu \\ Rajesh Paleti \\ The University of Texas at Austin \\ Dept of Civil, Architectural and Environmental Engineering \\ 1 University Station C1761, Austin TX 78712-0278 \\ Phone: 512-471-4535, Fax: 512-475-8744 \\ E-mail: rajeshp@mail.utexas.edu
Syndney Jenkins
Louisiana State University
Department of Civil and Environmental Engineering
3418 Patrick F. Taylor - LSU, Baton Rouge, LA 70803
Tel: 843-276-1348, Fax: 225-578-4945
Email: sjenki9@tigers.lsu.edu

\section{Chandra R. Bhat*}

The University of Texas at Austin

Dept of Civil, Architectural and Environmental Engineering

1 University Station C1761, Austin TX 78712-0278

Phone: 512-471-4535, Fax: 512-475-8744

E-mail: bhat@mail.utexas.edu

*corresponding author

June 13, 2012 


\begin{abstract}
The current study contributes to the already substantial scholarly literature on telecommuting by estimating a joint model of three dimensions- option, choice and frequency of telecommuting. In doing so, we focus on workers who are not self-employed workers and who have a primary work place that is outside their homes. The unique methodological features of this study include the use of a general and flexible generalized hurdle count model to analyze the precise count of telecommuting days per month, and the formulation and estimation of a model system that embeds the count model within a larger multivariate choice framework. The unique substantive aspects of this study include the consideration of the "option to telecommute" dimension and the consideration of a host of residential neighborhood built environment variables. The 2009 NHTS data is used for the analysis, and allows us to develop a current perspective of the process driving telecommuting decisions. This data set is supplemented with a built environment data base to capture the effects of demographic, work-related, and built environment measures on the telecommuting-related dimensions. In addition to providing important insights for policy analysis, the results in this paper indicate that ignoring the "option" dimension of telecommuting can, and generally will, lead to incorrect conclusions regarding the behavioral processes governing telecommuting decisions. The empirical results have implications for transportation planning analysis as well as for the worker recruitment/retention and productivity literature.
\end{abstract}

Keywords: Telecommuting, work-life balance, count data, generalized ordered response model, multivariate modeling. 


\section{INTRODUCTION}

The benefits and costs of telecommuting in terms of productivity, management, and family interaction considerations have been studied extensively in the psychology, management, and sociology fields, respectively (see Dambrin, 2004, Siha and Monroe, 2006, and Morganson et al., 2010). At the same time, the confluence of a need to reduce traffic congestion during the peak periods, as well as reduce vehicle miles of travel due to work-related travel (which contributes to green house gas (GHG) emissions from the transportation sector), has led planning organizations and regional governments to consider several demand management actions, one of them being the promotion of telecommuting. Thus, urban planners and transportation researchers have examined the potential impacts of telecommuting on regional land-use and travel patterns (see Choo et al., 2005, Ory and Mokhtarian, 2006, Tayyaran and Khan, 2007, and Ettema, 2010). For instance, from an urban planning perspective, a natural question that arises is whether telecommuting would lead to the urban sprawl of our societies (that is, will people with the option to telecommute relocate to residences that are not in close proximity to dense work locations). Similarly, from a transportation perspective, a question that arises is how will potential residential pattern shifts due to telecommuting, as well as telecommuting itself, impact travel patterns? In general, though the overall impacts of telecommuting on productivity, lifestyles, land-use, and travel can be complex (or should we say because of this), there is an interest in understanding who the people are who are likely telecommuters, and on exploring the influence of the land-use and transportation systems on telecommuting decisions. This is central not only to understanding the impacts of telecommuting, but also to predict the extent of telecommuting in the future, and to identify work place, land-use, and transportation-based policy instruments that may gainfully be used to influence the extent of telecommuting.

The current paper contributes to the telecommuting literature by modeling the actual observed choice and frequency of telecommuting using a revealed choice data set as obtained from the 2009 National Household Travel Survey (NHTS) data set. However, in addition, it considers the "option to telecommute" dimension as well. The "option to telecommute" is related to whether or not employers provide their employees the opportunity to telecommute, which may depend on the nature of the job, the state of the technology, and the organization structure of the employer. Of course, while these may be considered as "supply-side" issues, in the medium-tolong term, individuals themselves have the ability to prepare themselves and seek employers/jobs 
that provide them the opportunity to telecommute. Besides, in some cases, individual employees may have the autonomy to decide whether to have a telecommuting arrangement or not by themselves or jointly with their employer (Tremblay, 2002). Conditional on the option to telecommute, an employee's adoption (or choice) of telecommuting and the frequency of telecommuting may be viewed primarily as demand-side issues (i.e., based on employee preferences to telecommute).

Clearly, the modeling of the final observed practice of telecommuting must consider both the supply side and demand side issues in a joint framework, since employers' adoption of (or flexibility in providing autonomy regarding) telecommuting as perceived by the employee (the "supply" side) and employees' preference for telecommuting (the "demand" side) come together and determine employees' practice (choice and frequency) of telecommuting. In this regard, while there may always be the occasional work from home "bouts" by an employee who is not regularly allowed to telecommute, such bouts are likely to be far and few in-between if the employee feels that she/he does not have the option to telecommute on her/his job. Thus, the analyst may consider the choice and frequency of telecommuting as being available only to those who perceive that they have the option to telecommute. This is exactly the same as the issue of choice set formation in typical discrete choice models. As already emphasized in that literature, failure to properly specify the choice set can lead to biased choice model parameters, and a lack of robustness in parameter estimates (see Basar and Bhat, 2004).

Given the importance of this issue, it is indeed interesting to note that only two studies that we are aware of (Bernardino and Ben-Akiva, 1996 and Peters et al., 2003) consider both the demand-side and the supply-side dimensions of telecommuting. Specifically, Bernardino and Ben-Akiva (1996) examined, using a mid-1990 survey of employers and employees of 120 organizations who allowed telecommuting for at least some employees, the attributes of (a) any formal telecommuting program arrangement designed by the organization and whether this formal program was offered to employees (it was, however, not necessary that any formal program be in place within the organization), and (b) whether an employee telecommuted or not. Peters et al., 2003 also examined, using a 2001 work and information technology survey of 849 employees in the Netherlands, (a) whether an employee is provided the opportunity to telecommute by her/his employer, (b) whether the employee would like to telecommute, and (c) whether the employee actually practices telecommuting. In both of these earlier works, a person 
is considered to be a telecommuter if $\mathrm{s} / \mathrm{he}$ works from home at least once a week, which essentially ignores those who telecommute less frequently than once a week. Further, both these studies ignore the important dimension of telecommuting frequency. Unlike these two studies, the current study accommodates individuals who telecommute even once a month. Further, in contrast to all earlier telecommuting studies, the current paper examines the effects of land-use and transportation system attributes on telecommuting decisions, and also investigates the pitfalls of ignoring the supply side dimension (i.e., whether the employer offers the option of telecommuting) when analyzing the effects of exogenous variables on the choice and frequency dimensions of telecommuting.

In addition to the substantive issues discussed above, there also are two important methodological differences between the current paper and earlier telecommuting studies. First, earlier studies that have considered the telecommuting frequency dimension have done so using broad intervals (such as once a month, 2-4 times a month, 5-8 times a month, and $>=9$ times a month, or "once a year", "a few times a year", "once a month or more", "once a week or more", and "almost everyday"). In contrast, we use the actual count of telecommuting frequency on a per month basis. Using these raw monthly counts provides a much better picture of the extent of telecommuting than using interval-level data. Besides, the number of telecommuting days per month take values anywhere from one to 30 , and warrant treatment as counts rather than as discrete interval level data. Second, we develop a model formulation and estimation procedure that embeds the resulting count model for frequency within a multivariate equation system that jointly models all three dimensions of telecommuting - the option to telecommute, the choice of telecommuting, and the frequency of telecommuting - to account for the possible presence of common individual-specific unobserved factors that may impact the three decisions.

The remainder of the paper is organized as follows. The next section discusses the data source and describes the sample for analysis. Section 3 presents the modeling methodology. Section 4 interprets the empirical results. Finally, Section 5 concludes the study by presenting research highlights and identifying avenues for future research. 


\section{DATA SOURCE AND SAMPLE DESCRIPTION}

\subsection{Data Sources}

The primary data for the current study is drawn from the 2009 National Household Travel Survey (NHTS) conducted by the U.S. Department of Transportation during the period of March 2008 through May 2009 (see U.S. DOT-NHTS, 2009 for details). Several questions regarding employment were solicited in the survey from over 150,000 households in the U.S. In the current study, the focus is on individuals who indicated that (a) they worked for pay or profit in the week prior to the survey day, (b) were not self-employed, and (c) had a primary work location outside home. The question that formed the basis for determining whether the worker (as identified above) had the opportunity to telecommute was as follows: "Do you have the option of working at home instead of going into your primary workplace?". A positive response to this question led to another subsequent question: "How many times in the last month did you work only at home for an entire work day instead of traveling to your usual \{primary\} workplace?". This subsequent question formed the basis for constructing the choice and frequency of telecommuting dependent variables. To be specific, all the respondents who reported a non-zero value for the number of times they worked at home in the last month are coded as choosing to telecommute, and the corresponding actual positive count serves as the frequency variable.

\subsection{Sample Description}

In the current study, we focused on the NHTS sample corresponding to the San Francisco Bay area for two main reasons. First, the research team has developed an extensive set of built environment (BE) measures at the level of traffic analysis zones (TAZs) for the Bay area, which was used in the study to investigate the effects of residential TAZ characteristics on telecommuting behavior. ${ }^{1}$ Second, the research team has access to the California add-on data of the NHTS sample with information on the census tract of each household residence, which was used as the basis to merge the BE measures with the demographic and work-related characteristics of individuals and households obtained in the NHTS survey. The study area comprises nine counties, including Alameda, Contra Costa, Marin, Napa, San Francisco, San Mateo, Santa Clara, Solano, and Sonoma.

\footnotetext{
${ }^{1}$ See Bhat and Guo, 2007 for a description of the data sources and methodologies for computing the BE measures.
} 
In addition to BE measures such as length of bicycle lanes and highway lanes within each TAZ, we also developed several TAZ-level accessibility measures for the analysis. These accessibility measures are Hansen-type measures (Fotheringham, 1983) and are computed for the auto mode, using the land-use/demographic and level-of-service files obtained from the Metropolitan Transportation Commission (MTC). The accessibility measures take the form below:

$$
A_{i}^{d}=\left[\sum_{j=1}^{N}\left(\frac{E_{j}^{d}}{t_{i j}}\right)\right] / N,
$$

where $A_{i}^{d}$ denotes the accessibility from zone $i$ for activity type $d, E_{j}^{d}$ is the number of establishments of activity purpose $d$ in zone $j$ (except for the recreational purpose, where $E_{j}^{d}$ is the open space in acres in zone $j$ ), $t_{i j}$ is the travel time from zone $i$ to zone $j$ by auto and $N$ is the total number of TAZs in the San Francisco Bay area.

The final sample used for the analysis includes 2563 workers, of whom 582 workers (22.7\% of total work force) have the option to telecommute. Of the 582 workers who have the option to telecommute, 394 (about $68 \%$ of those with the telecommuting option and $15.4 \%$ of all workers) choose to telecommute. The number of telecommuters as a percentage of all workers (with a primary work place outside home) is similar to those reported in the Sener and Bhat (2010) study for the Chicago region (14\%) (after re-classifying workers who telecommute less than a month in the Sener and Bhat study as non-telecommuters, to be consistent with the telecommuter definition in the current paper). Among those who telecommute, the mean frequency of telecommuting per month of telecommuting is 6 days (the range is from 1 to 30 ). ${ }^{2}$

\section{METHODOLOGICAL FRAMEWORK}

\subsection{The Formulation}

Let $q(q=1,2, \ldots, Q)$ denote the index for individuals. The model structures for the option to telecommute and choice of telecommuting take the form of binary probit models as follows:

\footnotetext{
${ }^{2}$ The descriptive sample statistics for the exogenous variables in our analysis are suppressed here due to space considerations. Suffice it to say that the sample statistics are close to the corresponding population statistics for the San Francisco Bay region. Interested readers may refer to the supplementary document by Singh et al., 2012 available at: http://www.caee.utexas.edu/prof/bhat/ABSTRACTS/Telecommuting/SuppNote.pdf.
} 


$$
\begin{aligned}
& t_{q}^{*}=\boldsymbol{\beta}^{\prime} \boldsymbol{x}_{q}+v_{q}, t_{q}=1 \text { if } t_{q}^{*}>0 \text { and } t_{q}=0 \text { if } t_{q}^{*} \leq 0 \\
& c_{q}^{*}=\boldsymbol{\delta}^{\prime} \boldsymbol{w}_{q}+\varepsilon_{q}, c_{q}=1 \text { if } c_{q}^{*}>0 \text { and } c_{q}=0 \text { if } c_{q}^{*} \leq 0, c_{q} \text { observed if } t_{q}=1
\end{aligned}
$$

where $t_{q}$ and $c_{q}$ are binary variables indicating whether individual $q$ has the option to telecommute or not, and whether the individual chooses to telecommute or not, respectively; $t_{q}^{*}$ and $c_{q}^{*}$ are the underlying continuous latent propensities of the two observed binary variables $t_{q}$ and $c_{q}$ respectively; $\boldsymbol{\beta}$ and $\boldsymbol{\delta}$ are the vectors of parameters associated with the explanatory variables $\boldsymbol{x}_{q}$ and $\boldsymbol{w}_{q}$ (both including a constant); and $v_{q}$ and $\varepsilon_{q}$ are random error terms, independently and identically distributed across all individuals, which represent all the unobserved factors impacting the first two choice decisions respectively. The frequency dimension takes the form of a count, and is modeled using a generalized ordered-response (GOR) framework as follows:

$$
\begin{gathered}
y_{q}^{*}=\gamma^{\prime} z_{q}+\eta_{q}, y_{q}=k \text { if } \psi_{k-1, q}<y_{q}^{*}<\psi_{k, q}, \text { observed only if } t_{q}=1 \text { and } c_{q}=1 \\
\text { with } \psi_{q, k}=f_{k}\left(s_{q}\right)=\Phi^{-1}\left(e^{-\lambda_{q}} \sum_{l=0}^{k} \frac{\lambda_{q}^{l}}{l !}\right)+\alpha_{k}, \text { and } \lambda_{q}=e^{\varsigma^{\prime} s_{q}}, k \in\{0,1,2, \ldots \ldots\}
\end{gathered}
$$

In the above equation, $\Phi^{-1}$ denotes the inverse of the univariate cumulative standard normal function, $y_{q}$ is the count variable that represents the number of days individual $q$ telecommutes per month, and $y_{q}^{*}$ may be interpreted as the underlying latent continuous variable representing the long-term drive or propensity for telecommuting. This latent propensity is mapped to the observed count $y_{q}$ using the $\boldsymbol{\psi}_{q}$ vector, which is a vertically stacked column vector of thresholds $\left(\psi_{q,-1}, \psi_{q, 0}, \psi_{q, 1}, \psi_{q, 2}, \ldots, \psi_{q, K}\right)^{\prime}$. Note that $\psi_{q,-1}=-\infty$ and $\psi_{q, K}=\infty$. The thresholds are written as functions of individual-related attributes (in the vector $\boldsymbol{s}_{q}$ ) that moderate the translation of the long-term telecommuting propensity to the observed telecommuting frequency. In addition, these thresholds include the $\alpha_{k}$ terms that allow for the aligning of predicted and actual counts. The restriction $\alpha_{0}=0$ is imposed for identification given the parameterization of the $\psi_{q, k}$ terms. In addition, we identify a count value $k^{*}$ such that for all $k>k^{*}, \alpha_{k}$ is fixed at $\alpha_{k^{*}}$. With this specification of the threshold values, the GOR framework can predict the probability of an arbitrary count, similar to a traditional count model (see Castro et al., 2012 for 
more details). $\gamma$ and $\varsigma$ are the vectors of parameters corresponding to the vectors of observables $\boldsymbol{z}_{q}$ (not including a constant) and $\boldsymbol{s}_{q}$ (including a constant), respectively. $\eta_{q}$ is a random error term representing unobserved factors influencing the long-term propensity to telecommute and is assumed to be independently and identically distributed across individuals. ${ }^{3}$

As discussed earlier, we model all the decisions jointly to account for the possible presence of common individual-specific unobserved factors that may impact all three decisions. To do so, we assume that the three error terms $v_{q}, \varepsilon_{q}$, and $\eta_{q}$ in the equations corresponding to the three dimensions of telecommuting are realizations from a tri-variate normal distribution with mean $\boldsymbol{\mu}=[0,0,0]$ and correlation matrix $\sum=\left(\begin{array}{ccc}1 & \rho_{v \varepsilon} & \rho_{v \eta} \\ \rho_{v \varepsilon} & 1 & \rho_{\varepsilon \eta} \\ \rho_{v \eta} & \rho_{\varepsilon \eta} & 1\end{array}\right)$.

\subsection{Model Estimation}

Let $\Phi_{E}($.$) denote the cumulative distribution function of the E$-variate normal distribution. Then, the probability that individual $q$ does not have the option to telecommute is given by:

$$
\operatorname{Pr}\left[t_{q}=0\right]=\operatorname{Pr}\left[v_{q}<-\boldsymbol{\beta}^{\prime} \boldsymbol{x}_{q}\right]=\Phi\left(-\boldsymbol{\beta}^{\prime} \boldsymbol{x}_{q}\right)
$$

The probability that individual $q$ does not choose to telecommute even though she/he has the option to telecommute is given by:

$$
\begin{aligned}
\operatorname{Pr}\left[t_{q}=1, c_{q}=0\right] & =\operatorname{Pr}\left[0<\boldsymbol{\beta}^{\prime} \boldsymbol{x}_{q}+v_{q}, \boldsymbol{\delta}^{\prime} \boldsymbol{w}_{q}+\varepsilon_{q}<0\right] \\
& =\Phi\left[-\boldsymbol{\delta}^{\prime} \boldsymbol{w}_{q}\right]-\Phi_{2}\left[-\boldsymbol{\beta}^{\prime} \boldsymbol{x}_{q},-\boldsymbol{\delta}^{\prime} \boldsymbol{w}_{q}, \rho_{v \varepsilon}\right] \\
& =\Phi_{2}\left[\boldsymbol{\beta}^{\prime} \boldsymbol{x}_{q},-\boldsymbol{\delta}^{\prime} \boldsymbol{w}_{q},-\rho_{v \varepsilon}\right]
\end{aligned}
$$

The probability that individual $q$ telecommutes $k(k=1,2, \ldots, 30)$ times per month provided he/she has the option to telecommute and also chooses to telecommute is given by:

$$
\begin{aligned}
& \operatorname{Pr}^{*}\left[t_{q}=1, c_{q}=1, y_{q}=k\right]=\operatorname{Pr}\left[0<\boldsymbol{\beta}^{\prime} \boldsymbol{x}_{q}+v_{q}, 0<\boldsymbol{\delta}^{\prime} \boldsymbol{w}_{q}+\varepsilon_{q}, \psi_{q, k-1}<\boldsymbol{\gamma}^{\prime} \boldsymbol{z}_{q}+\eta_{q}<\psi_{q, k}\right] \\
& =\Phi_{3}\left[\boldsymbol{\beta}^{\prime} \boldsymbol{x}_{q}, \boldsymbol{\delta}^{\prime} \boldsymbol{w}_{q}, \psi_{q, k}-\boldsymbol{\gamma}^{\prime} \boldsymbol{z}_{q} ; \rho_{v \varepsilon},-\rho_{v \eta},-\rho_{\varepsilon \eta}\right]-\Phi_{3}\left[\boldsymbol{\beta}^{\prime} \boldsymbol{x}_{q}, \boldsymbol{\delta}^{\prime} \boldsymbol{w}_{q}, \psi_{q, k-1}-\boldsymbol{\gamma}^{\prime} \boldsymbol{z}_{q} ; \rho_{v \varepsilon},-\rho_{v \eta},-\rho_{\varepsilon \eta}\right]
\end{aligned}
$$

\footnotetext{
${ }^{3}$ The model in Equation (4) is a generalization of the usual count data model with a Poisson discrete distribution with mean $\lambda_{q}$. To see this, assume that $\alpha_{k}=0 \forall k$ and $\gamma=0$. Then, the probability expression in the GORP model of Equation (4) collapses to a Poisson model.

${ }^{4}$ The scale of each of the error terms must be set to 1 for identification resulting in a correlation matrix.
} 
The probabilities based on the above equation for all $k>0$ have to add up to $\operatorname{Pr}\left[t_{q}=1, c_{q}=1\right]=\Phi_{2}\left[\boldsymbol{\beta}^{\prime} \boldsymbol{x}_{q}, \boldsymbol{\delta}^{\prime} \boldsymbol{w}_{q}, \rho_{v \varepsilon}\right]$. However, because of the structure of the GOR model for telecommuting frequency, there is a non-zero probability assigned to the " $t_{q}=1, c_{q}=1, y_{q}=0$ " event given by the following expression:

$\operatorname{Pr}^{*}\left[t_{q}=1, c_{q}=1, y_{q}=0\right]=\Phi_{3}\left[\boldsymbol{\beta}^{\prime} \boldsymbol{x}_{q}, \boldsymbol{\delta}^{\prime} \boldsymbol{w}_{q}, \psi_{q, 0}-\boldsymbol{\gamma}^{\prime} \boldsymbol{z}_{q} ; \rho_{v \varepsilon},-\rho_{v \eta},-\rho_{\varepsilon \eta}\right]$

Thus, the probabilities $\operatorname{Pr}^{*}\left[t_{q}=1, c_{q}=1, y_{q}=k\right]$ for $k>0$ have to be scaled appropriately in this hurdle count setting to obtain the final probabilities:

$\operatorname{Pr}\left[t_{q}=1, c_{q}=1, y_{q}=k ; k>0\right]=\operatorname{Pr}^{*}\left[t_{q}=1, c_{q}=1, y_{q}=k ; k>0\right] \times S_{\text {factor }}$,

where $S_{\text {factor }}=\left(\frac{\Phi_{2}\left[\boldsymbol{\beta}^{\prime} \boldsymbol{x}_{q}, \boldsymbol{\delta}^{\prime} \boldsymbol{w}_{q}, \rho_{v \varepsilon}\right]}{\Phi_{3}\left[\boldsymbol{\beta}^{\prime} \boldsymbol{x}_{q}, \boldsymbol{\delta}^{\prime} \boldsymbol{w}_{q},-\left(\psi_{q, 0}-\gamma^{\prime} \boldsymbol{z}_{q}\right) ; \rho_{v \varepsilon}, \rho_{v \eta}, \rho_{\varepsilon \eta}\right]}\right)$

Further, because the count probabilities kick-in only for positive counts, we have to impose the normalization $\alpha_{1}=0$ in the threshold specification of Equation (4). The log-likelihood function can then be written as:

$$
\begin{aligned}
L L=\sum_{q=1}^{Q}\left[I \left[t_{q}=\right.\right. & \left.0] \times \ln \left(\operatorname{Pr}\left[t_{q}=0\right]\right)+I\left[t_{q}=1\right] \times I\left[c_{q}=0\right] \times \ln \left(\operatorname{Pr}\left[t_{q}=1, c_{q}=0\right]\right)\right] \\
& +\sum_{q=1}^{Q} \sum_{k=1}^{K}\left[M_{q, k} \times \ln \left(\operatorname{Pr}\left[t_{q}=1, c_{q}=1, y_{q}=k\right]\right)\right]
\end{aligned}
$$

where $I[$.$] is an indicator function which takes the value 1$ if the expression in the parenthesis is true, 0 otherwise, and $M_{q, k}=I\left[t_{q}=1\right] \times I\left[c_{q}=1\right] \times I\left[y_{q}=k\right]$. All the parameters are estimated by maximizing the log-likelihood function above and the corresponding asymptotic covariance matrix of the estimator can be obtained in the usual way as the inverse of the information matrix.

\section{EMPIRICAL RESULTS}

In this section, we present the results of the final specification of the joint model framework of telecommuting option, choice, and frequency. Several variables and functional forms for variables were considered before arriving at the final model specification. A few variables that were significant only at above the 0.05 level of significance were still retained because of their intuitive effects and potential to guide future research efforts. The results are discussed by each of the four variable categories: (1) individual demographics, (2) work characteristics, (3) 
household demographics, and (4) built environment (BE) measures. The focus is on the effects of these variables on the latent variables impacting the observed dimensions of telecommuting option, choice, and frequency.

In addition to the joint trivariate model of option, choice, and frequency, we also estimated a bivariate model of choice and frequency, assuming that everyone in the sample had the option to telecommute (as earlier telecommuting studies have considered). Due to space considerations, we do not present these results in this paper, though we comment on the bivariate model results at appropriate places.

Table 1 presents the results of the joint model of option, choice, and frequency. The first row of the table provides the values of the constants for the option and choice binary models. These constants do not have substantive interpretations, because they simply serve as overall adjustor terms to fit the data best given the exogenous variables. Notwithstanding this caveat, the highly statistically significant negative constant for the option dimension may be attributed, in part, to the high proportion (about 78\%) of individuals who do not have the option to telecommute.

\subsection{Individual Demographics}

Among the individual demographics, the effect of the "female" dummy variable indicates that women are less likely to have the option of telecommuting, but are more likely to choose to telecommute when they have the opportunity. ${ }^{5}$ The first finding is somewhat surprising, since women have been identified as a "target" group for adding diversity (or, perhaps more appropriately, maintaining equitable representation) in the workforce; thus, it would seem that employers would consider providing the teleworking option to women as a human resource strategy to increase the pool of women in the work force. This is particularly so because several studies have suggested that telecommuting is sought (and adopted), in part, to maintain a better work-family life balance; and also that women continue to bear a disproportionate share of family-oriented responsibilities as well as place a higher premium on work-life balance (see Golden, 2008, and Thompson and Aspinwall, 2009). However, there may also be other opposing forces at work. For instance, Safirova and Walls (2004) and McCrate (2005) suggest that

\footnotetext{
${ }^{5}$ As we will discuss later, the option effect mentioned here is only valid for women who have a one-way commute of less than or equal to 20 miles, though the choice effect is for all women.
} 
women, in general, have less access to work flexibility of any kind because of the lower autonomy and bargaining power they may wield in the market place (even after controlling for job characteristics). Interestingly, though, the positive effect of the "married female" variable reveals that the negative likelihood of women having the option to telecommute becomes less pronounced for married women, to the point that there is no statistically significant difference between a married woman and a man in how likely they are to have the option to telecommute. This is consistent with the notion that married women more aggressively seek (and are provided) the option to telecommute (relative to unmarried women). ${ }^{6}$ Of course, for all the reasons mentioned above, it is no surprise that women, when they have the opportunity to telecommute, are more likely to do so than are men. An important point to note here is that gender did not have any impact on the choice and frequency dimensions in the bivariate model we estimated (this was also the case in the bivariate models of Walls et al., 2007 and Tang et al., 2008). Essentially, when the option dimension is ignored, the lower ability of women to locate themselves in jobs where telecommuting is available as an option cancels out with the higher choice of telecommuting if provided the option, leading to the "incorrect" finding that gender has no role to play in telecommuting choice. The results in the current paper, on the other hand, clearly shed light on a demographic group (i.e., women) that would value the ability to telecommute, but do not seem to be provided much opportunity to do so. Employers who are looking for equitable representation as well as the "best and the brightest" minds may need to consider this issue as part of their workforce development and retention strategy, especially in an environment where it is being increasingly argued that a work force representative of the global market place of consumers is nothing short of a corporate necessity (Thompson and Aspinwall, 2009).

The age-related effects have an impact on both the option and frequency dimensions. Middle-aged individuals (36-50 years of age) are most likely to have the option to telecommute, but are less likely to do so frequently relative to individuals of other age groups who also have the option to telecommute. This may be reflecting the "power" position of middle-aged individuals with more "perks" associated with their jobs, but they may also hold senior management positions that require going in to work frequently.

\footnotetext{
${ }^{6} \mathrm{We}$ also tested the interaction of female and the presence of children in different age categories ( 0 to 5 years, 5 to 10 years, and 11 to 15 years). However, none of these came out to be even marginally statistically significant in all three telecommuting components.
} 
Individuals with higher education levels have more leverage and bargaining ability with their employers, thus having the ability to maintain the option to telecommute and adopt telecommuting. This result has also been found in earlier studies (see Peters et al., 2003, and Golden, 2008). However, most of the earlier studies do not explicitly model the effects of education levels on the option to telecommute, as we do here; rather, these earlier studies simply hypothesize the "option effect" based on the propensity to telecommute. In our own bivariate analysis, the coefficients on the education variables are positive and highly statistically significant on the choice dimension, since the option effects get transferred to the choice dimension. On the other hand, our results in Table 1 clearly show that, given the option to telecommute, there is no statistically significant difference in the choice to telecommute based on education levels. Next, workers who use the internet frequently are more likely to have the option to telecommute, a result that is reasonable given that strong internet skills lead to targeting jobs that provide the telecommuting option. In their study, Thompson and Aspinwall (2009) found that individuals with strong internet self-efficacy (defined as "ones' belief that she/he can successfully use the technology of the internet to accomplish her/his instrumental work tasks") are attracted to jobs with the telecommuting option. Again, the bivariate model is unable to disentangle the "option" dimension and "choice" dimension effects, and attributes all the internet self-efficacy impacts to the "choice" effect, while our model disentangles the effect into an option effect (as above) as well as a choice effect (individuals who use the internet frequently are also likely adopters when given the option, perhaps because of the higher perceived value of telework arrangements). Overall, the results show that ignoring the option dimension would suggest that employers can expect highly educated and internet-savvy individuals to start telecommuting more because of a company-wide policy to promote telecommuting, while our model results indicate that employers should be prepared to see a much broader base of their employees choosing to telecommute because of the policy. Finally, individuals who use the walk or bicycling modes have a higher probability of having the telecommuting option. People who prefer walking/biking are perhaps more health conscious and environment friendly, and thus look for jobs that provide them the option to telecommute. Again, the bivariate model that ignores the option dimension transfers the "option" effect of walking/biking to a "choice" effect. 


\subsection{Work Characteristics}

Part-time employed individuals ( $\leq 34$ hours per week) are less likely to have the telecommuting option compared to those working full-time ( $>34$ hours per week), perhaps a reflection of the fact that part-time employees already work for limited hours and employers are less willing to allow flexibility within the reduced hours of work. However, given the option to telecommute, parttime employees work more frequently from home compared to full-time employees. This is intuitive because part-time employees may have targeted the limited work duration arrangement because of work/family balance considerations and, so, when having the telecommuting option, will "jump" at it and telecommute frequently. The bivariate model that ignores the option dimension captures the "frequency" effect, but indicates, incorrectly, that there is no significant difference in telecommuting choice itself based on "part-time versus "full-time" work arrangements. As in the case of women, our trivariate model indicates that part-time employees are a group that particularly values the opportunity to telecommute, but are more likely not to have the opportunity. In the long run, this may create retention and motivation problems among part-time workers, and could result in overall productivity concerns.

Individuals who have a flexible work start time are not only more likely to have the option to telecommute, but also more likely to choose to telecommute given the option (see Walls et al., 2007, and Sener and Bhat, 2010). Indeed, the effect of flexible work start time on having the option to telecommute is strong and highly statistically significant. As suggested by Sener and Bhat (2010), individuals who value work flexibility will look for jobs that can provide them both temporal (work timing) and spatial (work location) flexibility. Our results here more directly support this hypothesis, because we model the "option" dimension explicitly, while Sener and Bhat (2010) could only speculate based on the effects of education on the "choice" and "frequency" dimensions. The results in Table 1 show clearly that the work flexibility impact is almost exclusively through the "option" dimension, and has little to no statistically significant impact on the choice and frequency to telecommute, given the option to telecommute.

The occupation type variables in Table 1, as obtained from the NHTS survey, are actually a combination of job type and industry type. The NHTS survey solicits occupation type in five broad categories: (1) Professional/managerial/technical (PMT), (2) Sales/services, (3) Clerical/Administrative, (4) Manufacturing/construction/maintenance/farming (MCMF), and (5) Other. In our analysis, we used the first category as the base, and specified four dummy variables 
for the remaining categories. However, the dummy variable for the "other" category was not significant, and so it is included in the base category. ${ }^{7}$ The results of the occupation type dummy variables indicate that individuals in sales/service, clerical/administrative support, and the MCMF occupation categories are less likely to have the option to telecommute compared to workers in professional, managerial or technical (PMF) jobs, perhaps because non-PMF jobs either require face-to-face interactions with workers/clients on a regular basis or involve physical work of some sort. Again, while Walls et al., 2007, and Zhou et al., 2009 also reach a similar conclusion based on the effects of occupation type on choice and frequency, our model results more directly disentangle the option, choice, and frequency effects of occupation type. Among those who have the option to telecommute and choose to telecommute, individuals in sales/service, PMF jobs, and "other" jobs have a higher propensity to telecommute than individuals involved in clerical/administrative and MCMF types of jobs.

The next set of variables relate to commute characteristics. While a legitimate argument could be made that such variables are endogenous to telecommuting related options and choices, we consider these variables as exogenous in this study (as have almost all earlier studies of telecommuting behavior analysis). ${ }^{8}$ The results related to commute trip characteristics show that individuals whose (one-way) commute distance is longer than 20 miles are more likely to have the option to telecommute, as well as a high propensity to telecommute and telecommute frequently (see also Mokhtarian and Meenakshisundaram, 2002). The coefficient on the interaction of the "female" dummy variable with one-way commute needs to be considered together with the effects of the "female" and "married female" variables discussed earlier. Essentially, the results indicate that the lower likelihood of women (relative to men) to have the option to telecommute is valid only for those with a commute distance of less than or equal to 20 miles. For women with a commute distance of more than 20 miles, there is effectively no statistically significant difference in the option availability relative to men with a commute

\footnotetext{
${ }^{7}$ Admittedly, the occupation type categorization in the NHTS data is very coarse. It also co-mingles industry type and job type. The effects of the occupation type variables should, therefore, be viewed with some caution, and only as broad characterizations of job and industry mix.

${ }^{8}$ More broadly speaking, there could be some validity to the argument that all work-related decisions (including telecommuting, work schedule flexibility, full time versus part-time) and residential location choice decisions should be modeled in one single joint model system that implicitly determines the choice of a work location and commute trip attributes. But such a framework would become unwieldy. Also, there is some suggestion in the literature (see Ellen and Hempstead, 2002, and Ory and Mokhtarian, 2006) that individuals tend to make their work/home location choices prior to decisions on telecommuting. Further exploration of this endogeneity issue is needed to inform modeling.
} 
distance of more than 20 miles. That is, gender differences in the availability of the telecommuting option vanish at long commute distances. The interaction effect of being in a professional/managerial/technical occupation and commute distance also shows that, in general, the differences between the occupation categories in their telecommuting option availability become statistically insignificant at commute distances of longer than 20 miles. The implication is that differences based on sex and occupation categories are not relevant at long commute distances.

\subsection{Household Demographics}

Among the household demographic variables, the presence of children aged 0-5 years in the household positively influences the option and choice dimensions of telecommuting. This is to be expected since either employers provide more flexibility to employees with small children at home as a family-friendly policy, or individuals with children consider only those jobs that provide them the option to work at home. Given the option, workers with children also choose to telecommute to take care of children and their travel/activity needs (see Tremblay, 2002 and Golden, 2008). However, the results suggest that workers with children at home telecommute only occasionally, presumably to avoid distractions in their work and to maintain balance between their familial responsibilities and work commitments (see Walls et al., 2007 for a similar result). A similar situation (avoiding distractions) may be the reason for the lower probability of telecommuting among individuals with non-working senior adults and other workers in the household (both these variables did not turn out to be even moderately statistically significant in the bivariate case).

Individuals belonging to households with high income $(>\$ 100 \mathrm{~K})$ are more likely to have the option to telecommute, presumably because they are "high up the ladder" and have autonomy in determining their work arrangement. The bivariate model that ignores the option dimension transfers the "option" effect entirely to the "choice" dimension, incorrectly suggesting that employers who allow a broad-based telecommuting policy will see more of the high income individuals embrace it than the low income individuals. Finally, within the category of household demographics, individuals in households with a higher number of vehicles are more likely to choose to telecommute, possibly because there is less disruption in carpooling or dropping off/picking up responsibilities during the commutes when there are more vehicles. 


\subsection{Built Environment (BE) Measures of Residential Traffic Analysis Zone (TAZ)}

In the current research study, several BE measures associated with the worker's TAZ are found to have moderately significant impacts on telecommuting behavior. Individuals living in urban and suburban areas are more likely to have the option of telecommuting than those living in rural areas and second cities, perhaps because of higher accessibility to telecommunication, wireless, and internet resources in urban and suburban areas. ${ }^{9}$ However, given the option to telecommute, individuals in rural areas are more likely to choose to telecommute, though telecommute less frequently.

Employees residing in neighborhoods with high household density are less likely to have the option to telecommute, while individuals in neighborhoods with a large population are less inclined to telecommute. Workers living in areas with high employee density are more likely to have the option of telecommuting. The results also suggest that individuals residing in traffic analysis zones (TAZs) with high mileage of bicycle lanes are more disposed to telecommute, and those residing in TAZs with high retail employment telecommute frequently. This last result may be a reflection of the opportunities during break time to be able to visit retail areas, which should increase the appeal for telecommuting.

The results in Table 1 indicate that several accessibility measures impact the choice to telecommute. Specifically, high accessibility to recreational, eat-out, religious, auto-repair centers, personal business, and medical centers implies a higher likelihood to telecommute, though there is no impact on the option to telecommute. Those who live closer to non-work and leisure activity opportunities attach more value to telecommuting, and so are more likely adopters. The lack of impact of BE measures along the option dimension is consistent with intuition, since there is no reason to believe that individuals who have the option to telecommunicate will be resident in TAZs with specific BE characteristics. The BE results also indicate that high accessibility to maintenance and employment opportunities at the residential end negatively impacts the choice to telecommute. Finally, under the category of BE measures individuals residing in TAZs with high bicycle accessibility to other zones telecommute more

\footnotetext{
${ }^{9}$ A "Second City" as used in the NHTS data, refers to secondary cities surrounding a major metropolitan area. However, they are not equivalent to suburbs of the metropolitan area, which are within the major metropolitan area boundary. "Second cities" are generally satellite cities outside the major city metropolitan area. They may be viewed as somewhere between a suburb and a rural area in built-up land-use density.
} 
frequently. This may be viewed as another proxy measure for the intensity and spatial compactness of residential-end activity opportunities, which increases telecommuting frequency if telecommuting is adopted.

A salient aspect of this paper is its inclusion of a host of BE measures, as just presented and discussed. Our results provide support for the notion that BE measures influence telecommuting choice, raising the possibility that land-use policies can be used as vehicles to promote telecommuting and reduce traffic congestion. However, when we removed the option dimension and modeled only the choice and frequency dimensions in a bivariate setting, none of the accessibility measure effects (as well as the household density, population, length of bicycle lanes, and the employment density effects) discussed above turned out to be statistically significant (even at a 0.15 level of significance) in the model. This is not surprising, and is a manifestation of the "choice set" effect on choice model results in discrete choice models. Essentially, when the pool of individuals who have the option of telecommuting is not appropriately constructed, the effect of variables on the choice dimension can get corrupted even if the variables do not impact the option dimension at all (as in the case of the accessibility measures in the current empirical analysis). A simple example will help to illustrate this point. Assume two zones A and B. Both are identical in BE measures, except that zone A offers a higher accessibility to eat-out places. Assume that there are 100 employees residing in each zone, with each employee in one zone having a replicate in the other zone. The fraction of employees who have the telecommuting option is $20 \%$. Of the 20 employees in zone A, say 15 telecommute (because the availability of eat-out places is a draw during work breaks and increases the value of telecommuting). However, only 5 employees in zone B telecommute. Then, when the option dimension is not considered, the model "sees" that $15 \%$ of employees telecommute in zone A, while $5 \%$ telecommute in zone $\mathrm{B}$. The differential in telecommuting percentages between zones $\mathrm{A}$ and $\mathrm{B}$ that the model has to work with and attribute to "eat-out accessibility" is $10 \%$, which is relatively small in magnitude and may not be adequate for the model to declare a clear statistical difference given sampling considerations. On the other hand, the choice model that operates only on the pool of individuals who have the telecommuting option would "see" that $75 \%$ of employees in zone A choose to telecommute (given the option) compared to only $25 \%$ of employees in zone B, providing a differential of $50 \%$ for the choice model to work with and attribute to "eat-out accessibility". This results in a high magnitude and statistically significant 
effect on the BE variable. Of course, this is just a simple example, but illustrates the potential pitfalls in terms of parameter estimation when the option dimension is not considered.

Overall, our results indicate that BE measures of the type used in this study do affect telecommuting choice. However, caution needs to be exercised before jumping to the definitive conclusion that improving non-work and bicycle accessibility will lead to higher telecommuting adoption. This is because of the spatial coarseness of our accessibility measures. It is perhaps likely that workers will also consider their immediate micro-urban form surroundings and "place aesthetics" in determining how appealing it is to work from home. Thus, for example, a land-use design that builds a five-storey food-court and thus increases "eat-out" accessibility may in fact lead to lower telecommuting, as workers may find that it disturbs their sense of quiet and aesthetic sight. Nonetheless, there is a suggestion that improving accessibility to non-work activities will contribute to higher rates of telecommuting choice among those who have the option. Of course, even if so, there may be other considerations such as an increase in mid-day trips.

\subsection{Telecommuting Frequency Count Model Threshold Specification}

The count threshold parameters include the threshold specific constants ( $\alpha_{k}$ values), as well as a constant and variables associated with the individual as part of the $\varsigma$ vector (see Equation (4)).

The threshold specific constants $\left(\alpha_{k}\right)$ in Table 1 do not have any substantive interpretations. However, their presence provides flexibility in the count model to accommodate high or low probability masses for specific frequency outcomes. As indicated in Section 3.1, identification is achieved by specifying $\alpha_{0}=0, \alpha_{1}=0$, and $\alpha_{k}=\alpha_{k^{*}} \forall k \geq k^{*}$. In the present specification, we initially set $k^{*}$ to 29 (telecommuting days per month), and progressively reduced $k^{*}$ to 9 (telecommuting days per month) based on statistical significance considerations and general data fit.

The elements in the $\varsigma$ vector are presented next in Table 1. The constant does not have any particular interpretation. For the other variables, a positive coefficient shifts all the thresholds toward the left of the telecommuting frequency propensity scale, which has the effect of increasing telecommuting frequency. Thus, the positive coefficient for high household income $(>\$ 100 \mathrm{~K})$ variable in the threshold parameterization suggests a higher telecommuting frequency 
among individuals who are in high income and large-sized households, and who prefer to walk. These effects may be explained in a manner similar to the effects of these variables on telecommuting option and choice.

\subsection{Correlation Matrix Elements and Likelihood Measures of Fit}

All the three parameters $\left(\rho_{v \varepsilon}, \rho_{\varepsilon \eta}, \rho_{v \eta}\right)$ in the correlation matrix $\Sigma$ (see Section 3) did not turn out to be statistically significant in our empirical analysis suggesting that, after controlling for the exogenous variables in the model, there are no remaining unobserved factor effects influencing the option, choice, and frequency dimensions. While the absence of unobserved correlation effects collapses the joint model into independent models of telecommuting option, telecommuting choice, and a hurdle model of telecommuting frequency, it is important to note that the joint model formulated in this paper needs to be estimated before one can arrive at this conclusion.

The log-likelihood value at convergence of the final joint model (which collapsed to independent models) is -2194.751 . The corresponding naïve value with only constants in the option and choice equations, and with only a constant in the $\varsigma$ vector for the count model, is -2833.371. Obviously, a log-likelihood ratio test indicates the important value provided by the explanatory variables in explaining the telecommuting option, choice, and frequency dimensions.

As has been discussed in earlier sections, this paper explicitly considers the option dimension of telecommuting, while almost all earlier studies in the field have ignored this dimension. The importance of considering the option dimension has already been discussed from the standpoint of model parameter estimation. But, ignoring the option dimension can, and in general will, also impact data fit. To compare the data fit measures of the model with all three dimensions (the trivariate model) and the model that ignores the option dimension (the bivariate model), we computed the predictive log-likelihood corresponding to the choice of telecommuting and the frequency of telecommuting from the trivariate model by noting the following: $\operatorname{Pr}\left[c_{q}=0\right]=\operatorname{Pr}\left[t_{q}=0\right]+\operatorname{Pr}\left[t_{q}=1, c_{q}=0\right]$,

$\operatorname{Pr}\left[c_{q}=1, y_{q}=k ; k>0\right]=\operatorname{Pr}\left[t_{q}=1, c_{q}=1, y_{q}=k ; k \geq 1\right]$

This predictive log-likelihood can then be compared with the log-likelihood at convergence for the bivariate model. The predictive log-likelihood from the trivariate model is -1705.718 , while 
that the convergent log-likelihood from the bivariate model is -1740.239 . Since these two models are non-nested, one can use a non-nested predictive likelihood ratio test to compare the two models. The difference in the adjusted rho-bar squared $\left(\bar{\rho}_{c}^{2}\right)$ values between the two models is $0.0007 .{ }^{10}$ The probability that this difference could have occurred by chance is less than $\Phi\left\{-[-2 \times 0.0007 \times L(C)+(65-32)]^{0.5}\right\}$. This value, with $L(C)=-2193.99$, is almost zero $(9.657$ $\times 10^{-10}$ ) indicating that the difference in adjusted rho-bar squared values between the two models is statistically significant and that the trivariate model is significantly superior to the bivariate model even from a data fit perspective.

\subsection{Elasticity Effects}

In this section, the elasticity effects of variables from the bivariate model of telecommuting choice and frequency (ignoring the option dimension and assuming everyone has the option to telecommute) and our trivariate model. As already discussed, we expect that the magnitudes of these elasticity effects will be different between the two models. At the same time, the elasticity effects provide a sense of the magnitude effects of variables on telecommuting frequency, while the results in the previous section do not do so directly.

We compute aggregate-level elasticity effects of variables on the expected number of telecommuting days per month. To do so, and using the notation already established in Section 3 , we write the expected number of telecommuting days per month for individual $q$ as follows:

$$
\begin{aligned}
& E\left(y_{q}\right)=\sum_{k=1}^{K} \operatorname{Pr}\left[t_{q}=1, c_{q}=1, y_{q}=k ; k>0\right] \times k(k=1,2, \ldots, 30)-\text { For the trivariate model } \\
& E\left(y_{q}\right)=\sum_{k=1}^{K} \operatorname{Pr}\left[c_{q}=1, y_{q}=k ; k>0\right] \times k(k=1,2, \ldots, 30)-{\text { For the bivariate model. }{ }^{11}}^{11}
\end{aligned}
$$

\footnotetext{
${ }^{10}$ The adjusted rho-bar squared value $\bar{\rho}_{c}^{2}$ is computed as $\bar{\rho}_{c}^{2}=1-[(L(\hat{\beta})-H) / L(C)]$, where $L(\hat{\beta})$ is the predictive log-likelihood for the trivariate model and the convergent log-likelihood for the bivariate model, $H$ is the number of model parameters excluding the constants in the binary models and the constant in the $\varsigma$ vector for the count model, and $L(C)$ is the log-likelihood from the bivariate model with only the constant in the binary choice model and the constant in the $\varsigma$ vector

${ }^{11}$ The hurdle set-up for the telecommuting frequency in the bivariate case is derived in the same way as that for the trivariate case.
} 
The expected values above are functions of variables in all the dimensions of telecommuting. If there are common variables across two or more dimensions, the variables will impact the expected value through all the dimensions. ${ }^{12}$

To compute the aggregate-level "elasticity" effect of a dummy exogenous variable, we change the value of the variable to one for the subsample of observations for which the variable takes a value of zero and to zero for the subsample of observations for which the variable takes a value of one. We then sum the shifts in the expected aggregate number of telecommuting days per month in the two subsamples after reversing the sign of the shifts in the second subsample, and compute the effective percentage change in the expected total number of telecommuting days per month across all individuals in the sample due to a change in the dummy variable from 0 to 1 . To compute the aggregate level "elasticity" effect of a multinomial exogenous variable (such as occupation type), we take the base category sub-sample and change the value of the variable from zero to one (for each specific non-base category) for all individuals in the base sub-sample. Subsequently, we compute the percentage change in the expected aggregate number of telecommuting days per month across all individuals in the base sub-sample. For the aggregate level "elasticity" effect of an ordinal variable, we increase the value of the variable by 1 and compute the percentage change in the expected total number of telecommuting days per month across all individuals in the sample. Finally, to compute the aggregate level "elasticity" effect of a continuous variable, we increase the value of the continuous variable by $20 \%$. The elasticity effects for both the bivariate and trivariate models are shown in Table 2.

The sign and the relative magnitude of the elasticity effects can be used to compare the effects of variables on expected number of telecommuting days per month. For variables that have an interaction effect with another variable, the elasticities are computed for all sub-groups characterized by the main and interaction effects. For example, the first set of variables in Table 2 correspond to combinations of gender, marital status, and commute distance, because there are interaction effects among these variables. Thus, six sub-groups are developed: (1) Male, one-way commute distance less than 20 miles, (2) Males, one-way distance more than 20 miles, (3)

\footnotetext{
${ }^{12}$ The elasticity effects here computed in this section provides the cumulative effect of variables on the expected number of days of telecommuting per month. While helpful in terms of the bottom line, the effects of variables on each individual dimension still provides insights for policy analysis, as already discussed in the previous section. The elasticity effects presented here are simply to illustrate the overall differences in magnitude effects between the bivariate model (that ignores the option dimension) and the trivariate model. One can further break down the elasticity effects shown here into separate components specific to each dimension of effect to gain more insights, but this is straightforward to do and we do not pursue this here to conserve on space.
} 
Unmarried female, one-way distance less than 20 miles, (4) Unmarried female, one-way distance more than 20 miles, (5) Married female, one-way distance less than 20 miles, and (6) Married female, one-way distance more than 20 miles, The elasticity effects are computed for these variables with respect to the first sub-group ("male, one-way commute distance $<20$ miles") as the base instance.

Table 2 provides the elasticity effects corresponding to all interaction-based effects, and then the effects for the other variables. The second row in the table indicates that, according to bivariate model, the number of telecommuting days per month for men who commute over 20 miles each way is, on average, about $182 \%$ more than the number of telecommuting days per month for men who commute less than or equal to 20 miles each way. The corresponding figure from the trivariate model of this paper is about $97 \%$. Thus, according to the bivariate model, men commuting more than 20 miles are, on average, three times as likely to telecommute relative to men commuting less than or equal to 20 miles, while the trivariate model indicates only about a two-fold increase. Other entries may be similarly interpreted. In the rest of this section, we will only highlight three key points from this table. First, there are many variables with (incorrect) zero elasticity effects in the bivariate model (because the variables were not statistically significant even at the 0.15 level of significance, and so were not included in the model specification of the bivariate model, as discussed in Section 4). This is particularly so for the $\mathrm{BE}$ measures, reinforcing the results from earlier that telecommuting models that do not consider the option dimension should be used with substantial caution for informing land-use policies and instruments. Second, for most variables that have an effect in both the bivariate and trivariate models, the effects are overstated in the bivariate model. This is because any choice effect in the bivariate model is "implemented" on the entire "population" of workers whether or not they have the option to telecommute, which magnifies the aggregate effects of variables. As can be observed, the overstated effects (differentials between the bivariate and trivariate model effects are quite high as a percentage of the "true" effects from the trivariate model (ranging from $2.22 \%$ to $141.24 \%$, with an average overstated effect of $60.82 \%$ ). Third, according to the trivariate model results, married women in professional/managerial/technical (PMT) jobs with a one-way commute of more than 20 miles have the most number of telecommuting days per month relative to other individuals. More generally, those with a one-way commute of more than 20 miles have a high number of telecommuting days per month. Other important positive drivers of 
telecommuting levels are flexible work start times and accessibility to personal business centers. The latter result is indeed very interesting, and suggests that employees who have good access to personal business centers feel particularly more comfortable working from home, perhaps due to access (when needed) to more advanced communication methods (such as video-conferencing) and even low-tech needs such as large-scale copying. This is an issue that needs further careful examination, since it can increase the penetration of telecommuters through good land-use mixing of residences and personal business centers (note that one cannot attribute this result to employers granting employees more opportunity to telecommute if the employee residence is close to personal business centers, or to telecommuting-oriented individuals locating themselves close to personal business centers). This is because the option dimension effect did not come out to be statistically significant in the trivariate model; this is a pure "worker choice of telecommuting if having the option" effect.

\section{CONCLUSIONS AND IMPLICATIONS}

The current study contributes to the already substantial literature on telecommuting by estimating a joint model of three dimensions- option, choice and frequency of telecommuting, The unique methodological features of this study include the use of a general and flexible generalized ordered-response (GOR) model to analyze the precise count of telecommuting days per month, and the formulation and estimation of a model system that embeds the count model within a larger multivariate choice framework. In doing so, a hurdle count structure is used within the multivariate structure (while hurdle count systems have been estimated by themselves, our recasting of the count model as a GOR model is the key to embedding the hurdle count structure within a larger multivariate framework). The model structure can be used in predictive mode (as we do in Section 4.7) to estimate the number of days that a person will telecommute in a month. The unique substantive aspects of this study include the consideration of the "option to telecommute" dimension, the use of a sample based on recent telecommuting behavior, and the consideration of a host of residential neighborhood built environment variables. In considering the option to telecommute dimension, we draw on literature from the family economics, management, and psychology literature on work-life balance considerations and how these considerations may be valued differently by different individuals. Along these lines, an area for further improvement on the substantive side is to incorporate a more detailed classification of 
employment industry and job type, as well as consider a host of employer-related variables and the interaction of employee-employer characteristics (see, for example, Peters et al., 2003 and Rose and Hensher, 2004). Another extension would be to include the possibility of center-based telecommuting, and modeling the option, adoption, and frequency of center-based telecommuting (jointly with the option, adoption, and frequency of home-based telecommuting). Unfortunately, data for these substantive improvements and extensions are not available in the 2009 National Household Travel Survey (NHTS) used in this study.

The empirical results have implications for transportation planning analysis as well as for the worker recruitment/retention and productivity literature. On the transportation planning side, the model can be used to predict telecommuting trends due to projected changes in demographics and employment-related variables (such as age, households with and without children, and work characteristics) in the U.S. population. On the worker recruitment/retention and productivity side, the model results can be used by employers to target specific employee groups to increase the extent of telecommuting. This is because our model distinguishes between the option and choice dimensions, providing important, even if indirect, information regarding who values telecommuting more (high likelihood to choose to telecommute if provided the option), but are the ones who are less likely to have the option (low likelihood of having the option). Such information can be used gainfully to have a productive work force, as well as to recruit a high quality and diversified work force to provide a competitive edge in the market place.

\section{ACKNOWLEDGEMENTS}

This research was partially funded by a Southwest Region University Transportation Center grant. The authors are grateful to Lisa Macias for her help in formatting this document. Three anonymous reviewers provided useful comments on an earlier version of the paper. 


\section{REFERENCES}

Basar G, Bhat CR (2004) A parameterized consideration set model for airport choice: an application to the San Francisco Bay area. Transportation Research Part B 38(10): 889-904.

Bernardino A, Ben-Akiva M (1996) Modeling the adoption of telecommuting: comprehensive framework. Transportation Research Record 1552: 161-170.

Bhat CR, Guo JY (2007) A comprehensive analysis of built environment characteristics on household residential choice and auto ownership levels. Transportation Research Part B 41(5): 506-526.

Castro M, Paleti R, Bhat CR (2012) A latent variable representation of count data models to accommodate spatial and temporal dependence: Application to predicting crash frequency at intersections. Transportation Research Part B 46(1): 253-272.

Choo S, Mokhtarian PL, Salomon I (2005) Does telecommuting reduce vehicle-miles-Traveled? An aggregate time series analysis for the U.S. Transportation 32(1): 37-64.

Dambrin C (2004) How does telework influence the manager-employee relationship? International Journal of Human Resource development \& Management 4(4): 358-74.

Ellen IG, Hempstead K (2002) Telecommuting and the demand for urban living: a Preliminary look at white-collar workers. Urban Studies 39(4): 749-766.

Ettema D (2010) The impact of telecommuting on residential relocation and residential preferences. The Journal of Transport and Land Use 3(1): 7-24.

Fotheringham AS (1983) Some theoretical aspects of destination choice and their relevance to production-constrained gravity models. Environment and Planning A 15(8): 1121-1132.

Golden L (2008) Limited access: Disparities in flexible work schedules and work-at-home. Journal of Family and Economic Issues 29(1): 86-109.

McCrate E (2005) Flexible hours, workplace authority, and compensating wage differentials in the U.S. Feminist Economics 11(1): 11-39.

Mokhtarian PL, Meenakshisundaram R (2002) Patterns of telecommuting engagement and frequency. Prometheus 20(1): 21-37.

Morganson VJ, Major DA, Oborn KL, Verive JM, Heelan MP (2010) Comparing telework locations and traditional work arrangements: differences in work-life balance support, job satisfaction and inclusion. Journal of Managerial Psychology 25(6): 578-595.

Ory DT, Mokhtarian PL (2006) Which came first, the telecommuting or the residential/job relocation? An empirical analysis of causality. Urban Geography 27(7): 590-609

Peters P, Tijdens KG, Wetzels C (2003) Employees' opportunities, preferences, and practices in telecommuting adoption. Information and Management 41(4): 469-482.

Rose JM, Hensher DA (2004) Modeling agent interdependency in group decision making. Transportation Research Part E, 40(1): 63-79.

Safirova E, Walls M (2004) What have we learned from a recent survey of teleworkers? Evaluating the 2002 SCAG Survey. Resources for the Future, Discussion Paper 04-43, Washington D.C. 
Sener I, Bhat CR (2010) A copula based sample selection model of telecommuting choice and frequency. Environment and Planning A 43(1): 126-145.

Siha SM, Monroe RW (2006) Telecommuting's past and future: a literature review and research agenda. Business Process Management Journal 12(4): 455-82.

Singh P, Paleti R, Jenkins S, Bhat CR (2012) Supplementary Note: Additional Information on Data Sources and Sample Description. Department of Civil, Architectural and Environmental Engineering, The University of Texas at Austin. Available at http://www.caee.utexas.edu/prof/bhat/ABSTRACTS/Telecommuting/SuppNote.pdf.

Tang W, Mokhtarian PL, Handy S (2008) The role of neighborhood characteristics in the adoption and frequency of working at home: empirical evidence from Northern California. Institute of Transportation Studies, University of California, Davis, Research Report UCDITS-RR-08-21.

Tayyaran MR, Khan AM (2007) Telecommuting and residential location decisions: combined stated and revealed preferences model. Canadian Journal of Civil Engineering 34(10): 13241333.

Thompson LF, Aspinwall KR (2009) The recruitment value of work/life benefits. Personnel Review 38(2): 195-210.

Tremblay DG (2002) Balancing work and family with telework? Organizational issues and challenge. Women in Management Review 17(3/4): 157-70.

U.S. Department of Transportation, Federal Highway Administration (2009). National Household Travel Survey. Available at: http://nhts.ornl.gov.

Walls M, Safirova E, Jiang Y (2007) What drives telecommuting? Relative impact of worker demographics, employer characteristics, and job types. Transportation Research Record 2010: 111-120.

Zhou L, Qing S, Winters L (2009) Telecommuting as a component of commute trip reduction program. Transportation Research Record 2135: 151-159.

\section{LIST OF TABLES}

Table 1 Estimation Results of Trivariate Model

Table 2 Elasticity Effect of Variables on Expected Number of Telecommuting Days 
Table 1. Estimation Results of Trivariate Model

\begin{tabular}{|c|c|c|c|c|c|c|}
\hline \multirow{2}{*}{ Explanatory Variables } & \multicolumn{2}{|c|}{ Option } & \multicolumn{2}{|c|}{ Choice } & \multicolumn{2}{|c|}{ Frequency } \\
\hline & Estimate & t-stat & Estimate & t-stat & Estimate & t-stat \\
\hline Constant & -2.503 & -13.507 & -2.106 & -2.863 & - & - \\
\hline \multicolumn{7}{|l|}{ Individual Demographics } \\
\hline Female & -0.246 & -2.111 & 0.292 & 2.295 & - & - \\
\hline Married female & $0.117^{*}$ & 1.036 & - & - & - & - \\
\hline Age (Base: 16 to 35 years) & & & & & & \\
\hline Age between 36 to 50 years & $0.074^{*}$ & 1.017 & - & - & -0.409 & -2.585 \\
\hline Education (Base: up to High School or College/Associate Degree) & & & & & & \\
\hline Bachelor's degree (BA, AB, BS) & 0.246 & 2.487 & - & - & 0.298 & 2.184 \\
\hline Graduate/Professional degree (MA, MS, MBA, MD, PhD, EdD, ID) & 0.256 & 2.519 & $0.196^{*}$ & 1.588 & - & - \\
\hline Internet usage & & & & & & \\
\hline Everyday & 0.328 & 2.455 & 0.584 & 2.008 & - & - \\
\hline Person made at-least one walk trip in the last week & $0.096^{*}$ & 1.187 & 0.482 & 3.235 & - & - \\
\hline Person made at-least one bicycle trip in the last week & 0.242 & 2.433 & - & - & - & - \\
\hline \multicolumn{7}{|l|}{ Work Characteristics } \\
\hline Part-time employment ( $\leq 34$ hours per week) & -0.249 & -2.177 & - & - & 0.787 & 4.166 \\
\hline Flexible work start time & 1.400 & 14.887 & $0.356^{*}$ & 1.339 & - & - \\
\hline \multicolumn{7}{|l|}{ Occupation (Base: professional/managerial/technical job and "other" jobs) } \\
\hline Sales/service & -0.397 & -2.882 & - & - & - & - \\
\hline Clerical/admin support & -0.465 & -3.525 & - & - & $-0.640^{*}$ & -1.757 \\
\hline Manufacturing/construction/maintenance/farming & -0.792 & -3.578 & - & - & $-1.353^{*}$ & -1.931 \\
\hline One-way commute distance more than 20 miles & 0.539 & 2.812 & 0.555 & 3.642 & 0.386 & 2.410 \\
\hline Female $\times$ One-way commute distance more than 20 miles & $0.208^{*}$ & 1.339 & - & - & - & - \\
\hline Professional/manager $\times$ One-way commute distance more than 20 miles & -0.635 & -3.241 & - & - & - & - \\
\hline
\end{tabular}

* The significance level of these parameters is lower than 0.05 , as can be observed from the t-statistic 
Table 1. (Contd.) Estimation Results of Trivariate Model

\begin{tabular}{|c|c|c|c|c|c|c|}
\hline \multirow{2}{*}{ Explanatory Variables } & \multicolumn{2}{|c|}{ Option } & \multicolumn{2}{|c|}{ Choice } & \multicolumn{2}{|c|}{ Frequency } \\
\hline & Estimate & t-stat & Estimate & t-stat & Estimate & t-stat \\
\hline \multicolumn{7}{|l|}{ Household Demographics } \\
\hline Presence of children less than or equal to 5 years & 0.223 & 2.364 & $0.170^{*}$ & 1.041 & -0.506 & -2.643 \\
\hline Presence of non-working senior adult ( $>65$ years old) & - & - & -0.793 & -2.785 & - & - \\
\hline Number of workers in the household & - & - & $-0.195^{*}$ & -1.915 & -0.310 & -2.296 \\
\hline Household income greater than $100 \mathrm{~K}$ dollars & 0.370 & 4.251 & - & - & - & - \\
\hline Number of vehicles in the household & - & - & $0.112^{*}$ & 1.764 & - & - \\
\hline \multicolumn{7}{|l|}{ BE Characteristics of Residential TAZ } \\
\hline \multicolumn{7}{|l|}{ TAZ Location (Base: Second City) } \\
\hline Rural area & - & - & $0.428^{*}$ & 1.409 & -0.781 & -2.417 \\
\hline Urban or suburban area & $0.163^{*}$ & 1.845 & - & - & - & - \\
\hline Household density (number of households per square mile) of the neighborhood/10000 & $-0.176^{*}$ & -1.909 & - & - & - & - \\
\hline Total population $/ 10000$ & - & - & $-0.409^{*}$ & -1.883 & - & - \\
\hline Employee density (number of workers per square mile) of the neighborhood/10000 & 0.515 & 2.136 & - & - & - & - \\
\hline Length (mileage) of bicycle lanes/10 & - & - & $0.202^{*}$ & 1.527 & - & - \\
\hline \multicolumn{7}{|l|}{ Employment opportunities in the neighborhood } \\
\hline Retail trade employment/1000 & - & - & - & - & 0.300 & 2.021 \\
\hline \multicolumn{7}{|l|}{ Accessibility measures } \\
\hline Employment accessibility/10 & - & - & $-0.089^{*}$ & -1.800 & $-0.078^{*}$ & -1.867 \\
\hline Accessibility to recreational (open spaces) opportunities/10 & - & - & 0.133 & 1.996 & - & - \\
\hline Accessibility to eat- out opportunities $\times 10$ & - & - & 0.589 & 2.042 & - & - \\
\hline Accessibility to religious opportunities $\times 10$ & - & - & 1.022 & 2.419 & - & - \\
\hline Accessibility to maintenance activities $\times 10$ & - & - & -1.161 & -2.474 & - & - \\
\hline Accessibility to automotive/carwash/repair centers $\times 10$ & - & - & $0.945^{*}$ & 1.913 & - & - \\
\hline Accessibility to personal business centers $\times 10$ & - & - & 1.199 & 2.523 & - & - \\
\hline Accessibility to medical centers $\times 10$ & - & - & 1.010 & 2.450 & - & - \\
\hline Number of zones accessible by bicycle from the home zone within 12 miles & - & - & - & - & $0.348^{*}$ & 1.710 \\
\hline
\end{tabular}

* The significance level of these parameters is lower than 0.05 , as can be observed from the t-statistic 
Table 1. (Contd.) Estimation Results of Trivariate Model

\begin{tabular}{|c|c|c|c|c|c|c|}
\hline \multirow{2}{*}{ Explanatory Variables } & \multicolumn{2}{|c|}{ Option } & \multicolumn{2}{|c|}{ Choice } & \multicolumn{2}{|c|}{ Frequency } \\
\hline & Estimate & t-stat & Estimate & t-stat & Estimate & t-stat \\
\hline \multicolumn{7}{|l|}{ "Threshold Variables } \\
\hline \multicolumn{7}{|l|}{ Threshold Specific Constants } \\
\hline$\alpha_{1}$ & - & - & - & - & 0.000 & - \\
\hline$\alpha_{2}$ & - & - & - & - & $-0.100^{*}$ & -1.564 \\
\hline$\alpha_{3}$ & - & - & - & - & -0.315 & -3.705 \\
\hline$\alpha_{4}$ & - & - & - & - & -0.408 & -3.921 \\
\hline$\alpha_{5}$ & - & - & - & - & -0.660 & -5.672 \\
\hline$\alpha_{6}$ & - & - & - & - & -0.962 & -7.570 \\
\hline$\alpha_{7}$ & - & - & - & - & -1.288 & -9.468 \\
\hline$\alpha_{8}$ & - & - & - & - & -1.442 & -9.331 \\
\hline$\alpha_{9}$ & - & - & - & - & -1.740 & -10.572 \\
\hline \multicolumn{7}{|l|}{$\varsigma$ Vector } \\
\hline Constant & - & - & - & - & 1.320 & 7.652 \\
\hline \multicolumn{7}{|l|}{ Individual Demographics } \\
\hline Person made at-least one walk trip in the last week & - & - & - & - & $-0.099^{*}$ & -1.379 \\
\hline \multicolumn{7}{|l|}{ Household Demographics } \\
\hline Household income greater than $100 \mathrm{~K}$ dollars & - & - & - & - & $0.094^{*}$ & 1.192 \\
\hline Household size & - & - & - & - & $0.040^{*}$ & 1.432 \\
\hline Number of parameters estimated & \multicolumn{2}{|c|}{22} & \multicolumn{2}{|c|}{22} & \multicolumn{2}{|c|}{24} \\
\hline Number of observations & \multirow{2}{*}{\multicolumn{6}{|c|}{$\begin{array}{r}2563 \\
-2194\end{array}$}} \\
\hline Joint log-likelihood at convergence & & & & & & \\
\hline
\end{tabular}

* The significance level of these parameters is lower than 0.05, as can be observed from the t-statistic 
Table 2. Elasticity Effect of Variables on Expected Number of Telecommuting Days

\begin{tabular}{|c|c|c|}
\hline \multirow{2}{*}{ Explanatory Variables } & Bivariate Model & Trivariate Model \\
\hline & Elasticity & Elasticity \\
\hline \multicolumn{3}{|l|}{ Interaction Effects } \\
\hline \multicolumn{3}{|l|}{ Individual demographics and commute distance } \\
\hline Males, one way commute distance less than or equal to 20 miles - Base Case & 0.000 & 0.000 \\
\hline Males, one way commute distance more than 20 miles & 182.579 & 97.554 \\
\hline Unmarried female, one-way distance less than or equal to 20 miles & 0.000 & -4.558 \\
\hline Unmarried female, one-way distance more than 20 miles & 182.579 & 93.580 \\
\hline Married female, one-way distance less than or equal to 20 miles & 0.000 & 2.736 \\
\hline Married female, one-way distance more than 20 miles & 182.579 & 112.203 \\
\hline \multicolumn{3}{|l|}{ Occupation type and commute distance } \\
\hline Professional/manager/technical job and one way commute distance less or equal to 20 miles - Base Case & 0.000 & 0.000 \\
\hline Professional/manager/technical job and one way commute distance more than 20 miles & 178.799 & 99.929 \\
\hline Clerical/Admin. Support job and one way commute distance less than or equal to 20 miles & -70.085 & -41.814 \\
\hline Clerical/Admin. Support job and one way commute distance more than 20 miles & 5.894 & 10.308 \\
\hline Sales/Service job and one way commute distance less than or equal to 20 miles & -43.597 & -23.847 \\
\hline Sales/Service job and one way commute distance more than 20 miles & 98.574 & 54.790 \\
\hline Manufacturing/construction/maintenance job and one way commute distance less than or equal to 20 miles & -79.872 & -51.275 \\
\hline Manufacturing/construction/maintenance job and one way commute distance more than 20 miles & -24.560 & -15.900 \\
\hline \multicolumn{3}{|l|}{ Individual Demographics } \\
\hline \multicolumn{3}{|l|}{ Age } \\
\hline Age between 36 to 50 years & -17.743 & -10.264 \\
\hline \multicolumn{3}{|l|}{ Education (Base: up to High School or College/Associate Degree) } \\
\hline Bachelor's degree (BA, AB, BS) & 30.031 & 24.969 \\
\hline Graduate/Professional degree (MA, MS, MBA, MD, PhD, EdD, ID) & 19.056 & 19.421 \\
\hline \multicolumn{3}{|l|}{ Internet usage } \\
\hline Everyday & 28.730 & 28.105 \\
\hline Person made at-least one walk trip in the last week & 5.244 & 9.286 \\
\hline Person made at-least one bicycle trip in the last week & 16.438 & 12.177 \\
\hline
\end{tabular}


Table 2. (Contd.) Elasticity Effect of Variables on Expected Number of Telecommuting Days

\begin{tabular}{|c|c|c|}
\hline \multirow{2}{*}{ Explanatory Variables } & Bivariate Model & Trivariate Model \\
\hline & Elasticity & Elasticity \\
\hline \multicolumn{3}{|l|}{ Work Characteristics } \\
\hline Part-time employment ( $\leq 34$ hours per week) & 52.317 & 23.472 \\
\hline Flexible work start time & 88.743 & 83.784 \\
\hline \multicolumn{3}{|l|}{ Household Demographics } \\
\hline Presence of children less than or equal to 5 years & -5.172 & -5.462 \\
\hline Presence of non-working senior adult ( $>65$ years old) & 0.000 & -17.048 \\
\hline Number of workers in the household & 0.000 & -17.870 \\
\hline Household income greater than $100 \mathrm{~K}$ dollars & 33.319 & 27.207 \\
\hline Number of vehicles in the household & 0.000 & 4.295 \\
\hline Household size & 0.000 & 4.170 \\
\hline \multicolumn{3}{|l|}{ BE Characteristics of Residential TAZ } \\
\hline \multicolumn{3}{|l|}{ TAZ Location (Base: Second City) } \\
\hline Rural areas & -33.476 & -13.877 \\
\hline Urban or suburban area & 0.000 & 7.655 \\
\hline Household density (number of households per square mile) of the neighborhood & 0.000 & -0.488 \\
\hline Total population & 0.000 & -1.824 \\
\hline Employee density (number of workers per square mile) of the neighborhood & 0.000 & 5.172 \\
\hline Length (mileage) of bicycle lanes & 0.000 & 1.149 \\
\hline \multicolumn{3}{|l|}{ Employment opportunities in the neighborhood } \\
\hline Retail trade employment & 1.118 & 1.041 \\
\hline \multicolumn{3}{|l|}{ Accessibility measures } \\
\hline Employment accessibility & 0.000 & -4.799 \\
\hline Accessibility to recreational (open spaces) opportunities & 0.000 & 8.467 \\
\hline Accessibility to eat- out opportunities & 0.000 & 10.922 \\
\hline Accessibility to religious opportunities & 0.000 & 5.802 \\
\hline Accessibility to maintenance activities & 0.000 & -37.637 \\
\hline Accessibility to automotive/carwash/repair centers & 0.000 & 15.202 \\
\hline Accessibility to personal business centers & 0.000 & 93.428 \\
\hline Accessibility to medical centers & 0.000 & 64.890 \\
\hline Number of zones accessible by bicycle from the home zone within 12 miles & 0.000 & 1.817 \\
\hline
\end{tabular}

